\author{
Y \\ VERSITA 10.2478/v10310-012-0025-2 \\ Ovidius University Annals of Chemistry \\ Volume 23, Number 2, pp. 149-154, 2012

\section{Regeneration of used engine lubricating oil by solvent extraction} \\ Ancaelena-Eliza STERPU ${ }^{\mathrm{a} *}$, Anca Iuliana DUMITRU ${ }^{\mathrm{a}}$ and Mihai-Florinel POPA ${ }^{\mathrm{b}}$ \\ ${ }^{a}$ Ovidius University of Constanta, Department of Chemistry and Chemical Engineering, 124 Mamaia Blvd, \\ 900527 Constanta, Romania \\ b “Auto Axel” Ltd., W. Maracineanu Str, No. 7, Postal code: 700373 - Iaşi, Romania
}

\begin{abstract}
Huge amounts of used lubricating oils from automotive sources are disposed of as a harmful waste into the environment. For this reason, means to recover and reuse these wastes need to be found. Problems arising from acid treatment include environmental problems associated with the disposal of acid sludge and spent earth, low product yield (45-65\%) and incomplete removal of metals. The processes of re-refining of used lubricating oils depend greatly on the nature of the oil base stock and on the nature and amount of contaminants in the lubricant resulting from operations. The study was carried out on a sample of $15 \mathrm{~W} 40$ type used oil collected from one automobile. The re-refining process of used oil consists of dehydration, solvent extraction, solvent stripping and vacuum distillation. This study aims to investigate a process of solvent extraction of an alcohol-ketone mixture as a pre-treatment step followed by vacuum distillation at $5 \mathrm{mmHg}$. The primary step was conducted before the solvent extraction that involves dehydration to remove the water and fuel contaminants from the used oil by vacuum distillation. The solvent extraction and vacuum distillation steps were used to remove higher molecular weight contaminants.

The investigated solvent to oil ratios were 2, 3, 4, 5 and 6. The solvent composition is 25\% 2-propanol, 50\% 1butanol and $25 \%$ butanone or methyl ethyl ketone (MEK). The percentage of oil recovery for the solvent to oil ratio of $6: 1$ is further improved, but for the ratio values higher than 6:1, operation was considered economically not feasible. Finally, the re-refined oil properties were compared with the commercial virgin lubricating oil properties.
\end{abstract}

Keywords: regeneration used oil, solvent extraction, vacuum distillation, ash content

\section{Introduction}

Large and increasing amounts of lubricating oil are produced each year that, after use, are considered a hazardous waste because of their high content of pollutants (thermal degradation products from the base oil and additives and combustion products from the fuel and lubricant). Nevertheless, the used oil still contains a large proportion of valuable base oil that may be used to formulate new lubricants if undesirable pollutants are separated from the oil by an appropriate recycling procedure $[1,2]$. Thus, not only environmental but also economic reasons justify the waste oil regeneration process.

The principal obstacle of regeneration process is that cleaning used motor oil by filtering at centrifuge does not ensure that the fine particles formed during aging $(0.5-5.0 \mu \mathrm{m})$, are totally removed. Those contaminants can form sludge and promote the formation of varnish, carbon deposits, and other deposits on engine parts, thus shortening their service life. Clarification of oil during cleaning to remove mechanical impurities and water is a necessary operation in the technology of reprocessing collected oil, although this does require special conditions and materials and improved equipment. [3].

\section{Experimental}

The experimental procedure of solvent extraction process is presented schematically in 
Fig.1.

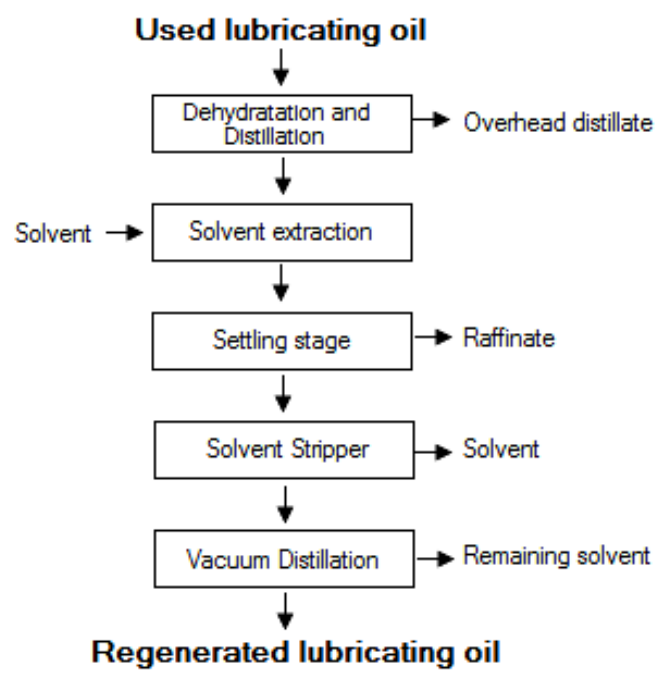

Fig.1. Oil regeneration process

\subsection{Dehydration}

The dehydration of used lubricating oil was performed in a simple batch vacuum distillation (Fig. 2) to eliminate water and light hydrocarbons (gasoline). In this process used lubricating oil is first filtrated to remove debris and other solid particles.

Water and gasoline fractions were separated under vacuum at $5 \mathrm{mmHg}$ and $210^{\circ} \mathrm{C}$ (atmospheric equivalent temperature). Distillation was carried out until no further distillate was produced. The dehydrated used oil was collected and then used for the next step of solvent extraction. amount of $100 \mathrm{~mL}$ for each experiment.

The solvent composition was fixed to one part 2-propanol, two parts 1-butanol and one part MEK (25\% vol. 2-propanol, $50 \%$ vol. 1-butanol and $25 \%$ vol. MEK) as reported by some authors [4-8]. The main solvent properties are presented in Table.1.

According to Table 1 there are three solvents that presents large differences in boiling point temperature of two of the solvents, i.e., 2-propanol $\left(82^{\circ} \mathrm{C}\right)$ and $\mathrm{MEK}\left(80^{\circ} \mathrm{C}\right)$, compared with the third solvent 1-butanol $\left(118^{\circ} \mathrm{C}\right)$. Thus, all atmospheric distillation experiments failed to recover all the solvent amounts at temperature below $250^{\circ} \mathrm{C}$, which is the degradation temperature of the oil, while 2-propanol and MEK were successfully recovered at $200^{\circ} \mathrm{C}$.

The investigated solvent to oil ratios were $(2$, $3,4,5$ and 6). Solvent to oil ratio less than 2 produced viscous mixture during separation. For a solvent to oil ratio higher than 6 to 1 , operation is considered economically not feasible. According to these considerations the solvent amounts added were $(200,300,400,500$ and $600 \mathrm{~mL})$.

The extraction process was performed with an extraction cell provided with an agitator, at room temperature. Adequate mixing of the solvent-oil mixture was obtained by stirring for 30 minutes at $2.5 \mathrm{rot} / \mathrm{s}$. The mixture was allowed to settle for 24 hours in order to separate the extract phase (solvents and base oil components dissolved) from the raffinate phase (contaminants or sludge). Separation of the two phases was carried out in 1 liter separating funnels. The extract phase was red to brown in color and of low viscosity, while the raffinate phase was black and semisolid.

\subsection{Solvent Extraction}

The dehydrated used oil was prepared in

Table 1. The main solvent properties

\begin{tabular}{|l|l|l|l|}
\hline Test & 2-propanol & 1-butanol & MEK \\
\hline Formula & $\mathrm{C}_{3} \mathrm{H}_{7} \mathrm{OH}$ & $\mathrm{C}_{4} \mathrm{H}_{9} \mathrm{OH}$ & $\mathrm{C}_{4} \mathrm{H}_{8} \mathrm{O}$ \\
\hline Molecular weight, g/mol & 60.1 & 74.12 & 72.11 \\
\hline Density, g/cm ${ }^{3}$, at $20^{\circ} \mathrm{C}$ & 0.786 & 0.81 & 0.8050 \\
\hline Viscosity, cP at $20^{\circ} \mathrm{C}$ & 2.46 & 3 & 0.43 \\
\hline Refractive index, $\mathrm{n}_{\mathrm{d}}{ }^{20}$ & 1.3776 & 1.399 & 1.3788 \\
\hline Boiling point, ${ }^{\circ} \mathrm{C}$ & 82 & 118 & 80 \\
\hline Pour point, ${ }^{\circ} \mathrm{C}$ & -89 & -90 & -86 \\
\hline Solubility in water g/L & miscible & 63.2 & 275 \\
\hline
\end{tabular}


This procedure was repeated in all experiments for every solvent to oil ratio. The extract phase was subjected to simple batch atmospheric distillation to recover the solvent from the oil by heating up to $200^{\circ} \mathrm{C}$.

\subsection{Vacuum distillation}

The vacuum distillation operation is done to recover the remaining 1-butanol from the amount of used oil after the solvent extraction process.

The vacuum distillation experiments were carried out according to ASTM D 1160 - 03 by the vacuum distillation apparatus described in Fig.2.

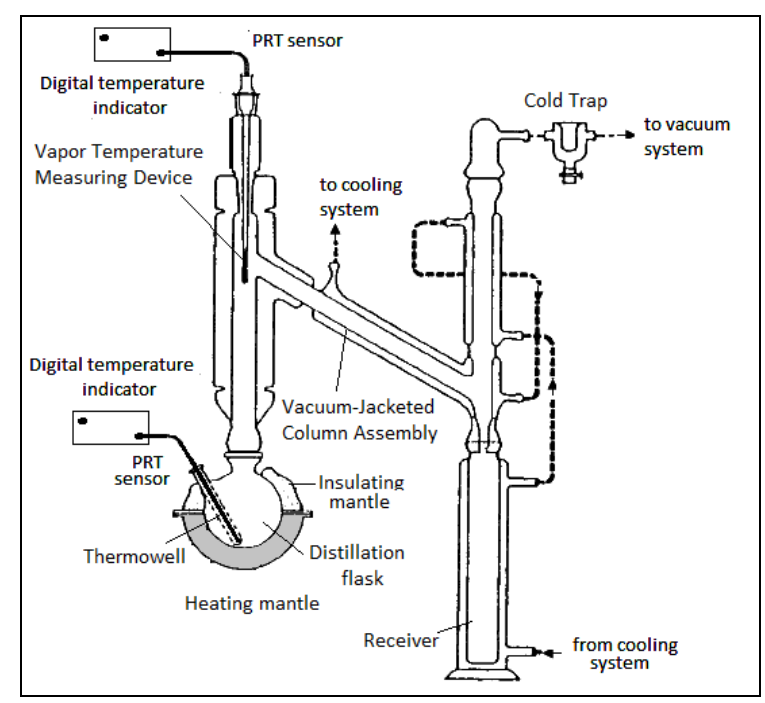

Fig.2. Vacuum distillation apparatus

The operation conditions of the vacuum distillation process of the treated oil were at $5 \mathrm{~mm}$
$\mathrm{Hg}$ and $190^{\circ} \mathrm{C}$ to minimize cracking and to maximize yield.

After each experiment, the vacuum distillation apparatus was washed with $n$-hexane solvent in order to remove any contaminants that accumulated in the column, condenser and vacuum lines. The $n$ hexane washed the contaminants and accumulated them at the bottom of the still pot where they can be removed. After washing, all connections and joints were re-lubricated, and prepared for the next experiment.

\section{Results and Discussions}

Used lubricating oil was analyzed to investigate density, cinematic viscosity, flash point and ash content. The analysis and tests used for analyzing the oil samples to evaluate their properties were done according to the standard methods as shown in Table 2.

Flash point of the used oil showed evidence of gasoline presence in the used oil, which has to be removed by distillation during the dehydration process. The best dehydration results are obtained at lower vacuum pressure and even though there is a wide range in boiling point between water, gasoline and the base oil cut. Also lower vacuum pressure is preferred to ensure that the temperature will not rise above $250^{\circ} \mathrm{C}$, which is the oil degradation temperature.

The final dehydration temperature depends on the amount of water and gasoline fractions in the used oil. The concentration of light hydrocarbons after this treatment was expected to be negligible.

Table 2. Used lubricating oil properties

\begin{tabular}{|l|l|l|l|}
\hline Test & Method & Apparatus & Value \\
\hline Density, $\left(\mathrm{g} / \mathrm{cm}^{3}\right)$ at $20^{\circ} \mathrm{C}$ & ASTM D 7042 & $\begin{array}{l}\text { Anton Paar SVM } \\
3000\end{array}$ & 0.896 \\
\hline Viscosity, $(\mathrm{cSt})$ at $20^{\circ} \mathrm{C}$ & ASTM D 7042 & $\begin{array}{l}\text { Anton Paar SVM } \\
3000\end{array}$ & 89 \\
\hline Ash content \% wt. & ASTM D 482-03 & - & 2.39 \\
\hline Flash point, ${ }^{\circ} \mathrm{C}$ & ISO 2592 & Marcusson open cup & 184 \\
\hline
\end{tabular}


Both types of compounds are undesirable for the formulation of new lubricants. Elimination of water was also necessary because it may modify the solubility parameter of base oil components in solvent.

The amounts of water and gasoline separated in all dehydration experiments were small due to low fuel dilution.

The results for mass balance for the optimum solvent to oil ratio experiments are tabulated in Table 3 while the tests percent of oil recovery and of ash content are presented in Table 4. The properties of produced solvent treated oil, i.e., oil recovery, solvent recovery and ash reduction in relation to solvent to oil ratio are shown in Fig. 3. The percentage of oil recovery for the solvent to oil ratio of $6: 1$ is further improved, but this solvent to oil ratio produces an ash reduction lower than that obtained for the solvent to oil ratio of $4: 1$ and $5: 1$ as shown in Fig. 3.

Ratios above 3:1 were not considered economically feasible by industry, but considering that the solvent can be recovered and reused, the ratio of 4:1 was considered to be the better solvent to oil ratio for treatment of used lubricating oil following this study.

The results of the investigation, Table 4 and Fig. 3 indicate that the maximum ash reduction is achieved for solvent to oil ratio of $4: 1$. The oil recovery and ash reduction for the some ratio are better than that obtained for solvent to oil ratio of $3: 1$ and $2: 1$. This indicates that by increasing the solvent amount, the solvency power is improved.

Table 3. Measurements of mass balance for optimum solvent to oil ratio experiments

\begin{tabular}{|c|c|c|c|c|c|c|c|}
\hline \multirow{2}{*}{$\begin{array}{c}\text { Solvent to oil } \\
\text { ratio }\end{array}$} & $\begin{array}{c}\text { Oil feed } \\
(\mathrm{mL})\end{array}$ & $\begin{array}{c}\text { Solvent } \\
(\mathrm{mL})\end{array}$ & $\begin{array}{c}\text { Extract } \\
(\mathrm{mL})\end{array}$ & $\begin{array}{c}\text { Raffinate } \\
(\mathrm{mL})\end{array}$ & \multicolumn{2}{|c|}{$\begin{array}{c}\text { Oil } \\
(\mathrm{mL})\end{array}$} & $\begin{array}{c}\text { Solvent } \\
(\mathrm{mL})\end{array}$ \\
\hline $2: 1$ & 100 & 200 & 265.4 & 34.6 & 78.3 & 185.2 & $\begin{array}{c}\text { Loss } \\
(\mathrm{mL})\end{array}$ \\
\hline $3: 1$ & 100 & 300 & 373.9 & 26.1 & 86.4 & 285.7 & 1.8 \\
\hline $4: 1$ & 100 & 400 & 478.8 & 21.2 & 92.3 & 384.9 & 1.6 \\
\hline $5: 1$ & 100 & 500 & 587.8 & 12.2 & 95.5 & 490.8 & 1.5 \\
\hline $6: 1$ & 100 & 600 & 690.7 & 9.3 & 96.1 & 593 & 1.6 \\
\hline
\end{tabular}

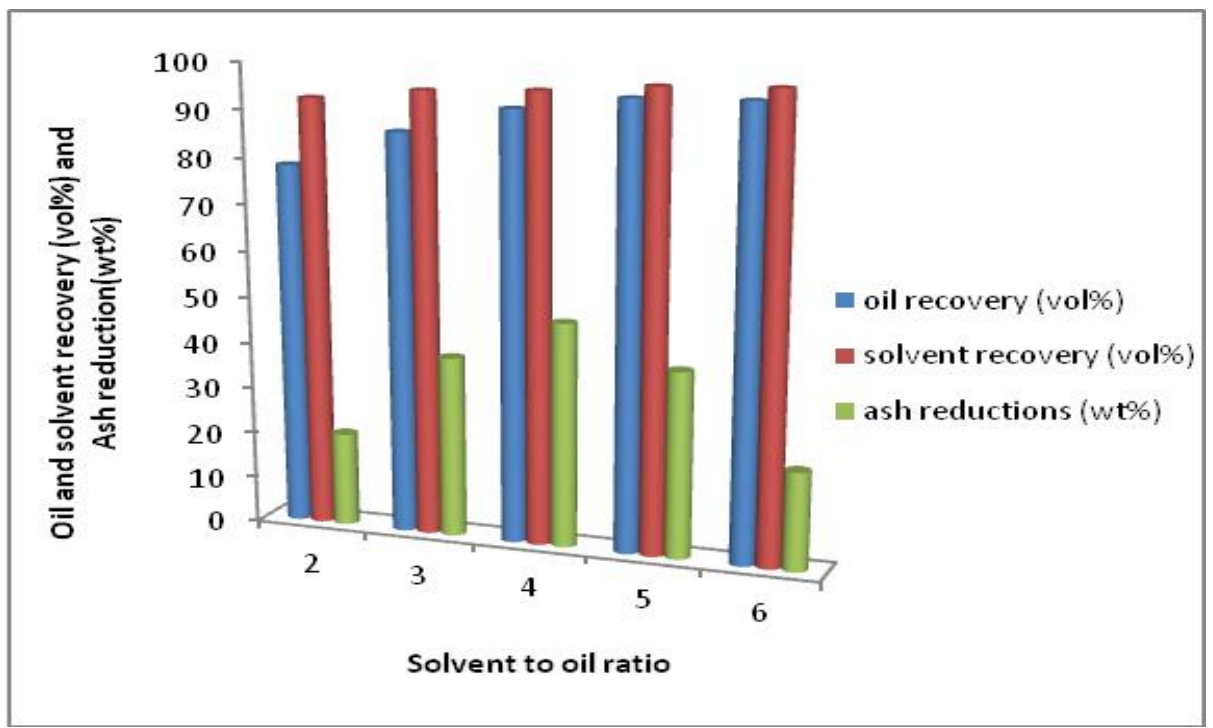

Fig. 3. The percentage of oil recovery, solvent recovery and ash reduction $v s$. solvent to oil ratio 
Table 4. Test analysis of the optimum solvents to oil ratio experiments

\begin{tabular}{|l|l|l|l|l|l|}
\hline Solvent to oil ratio & $2: 1$ & $3: 1$ & $4: 1$ & $5: 1$ & $6: 1$ \\
\hline Oil recovery (vol \%) & 78.3 & 86.4 & 92.3 & 95.5 & 96.1 \\
\hline Ash content (wt\%) & 1.91 & 1.45 & 1.23 & 1.42 & 1.87 \\
\hline
\end{tabular}

Table 5. Comparison between virgin oil and solvent treated oil properties

\begin{tabular}{|c|c|c|c|}
\hline Test & Method & Virgin oil & Solvent treated oil \\
\hline Density, $\left(\mathrm{g} / \mathrm{cm}^{3}\right)$ at $20^{\circ} \mathrm{C}$ & ASTM D 7042 & 0.890 & 0.890 \\
\hline Viscosity, $(\mathrm{cSt})$ at $20^{\circ} \mathrm{C}$ & ASTM D 7042 & 117.5 & 98.4 \\
\hline Ash content $\%$ wt. & ASTM D 482-03 & 1.3 & 1.23 \\
\hline Flash point, ${ }^{\circ} \mathrm{C}$ & ISO 2592 & 225 & 212 \\
\hline
\end{tabular}

A comparison between virgin oil and solvent treated oil (at solvent to oil ratio of 4:1) is presented in Table 5 which shows that the solvent treated oil contains less impurities than virgin oil as indicated the lower ash content and the same density value.

The solvent extraction process can be followed by clay treatment or hydro treatment to improve color and odor of regenerated oil.

\section{Conclusions}

Four process stages were studied, namely: dehydration, solvent extraction, solvent stripping, and vacuum distillation. The study was carried out on a sample of 15W40 type used oil collected from one automobile.

All gasoline and water fractions were separated using vacuum distillation at $5 \mathrm{~mm} \mathrm{Hg}$ and $210^{\circ} \mathrm{C}$ for the dehydration process.

Solvent to oil ratio of 4 to 1 with solvent composition of 25\% 2-propanol, 50\% 1-butanol and $25 \%$ MEK were found to be the optimum composition for solvent extraction. Solvent stripping was conducted by two stages: atmospheric distillation to recover 2-propanol and MEK solvents and vacuum distillation at $5 \mathrm{~mm} \mathrm{Hg}$ to remove the remaining 1-butanol.

Extraction reduces the contaminants (inorganic materials) to low level, i.e. $49 \%$ ash reduction, such that no further operational problems were encountered on vacuum distillation.
The best oil recovery and ash reduction by extraction were obtained using optimum evaluated solvent to oil ratio of 4 to 1 with solvent composition of 25\% 2-propanol, 50\% 1-butanol and 25\% MEK were $49 \%$ ash reduction and $92 \%$ oil recovery. That means that solvent to oil ratio larger than $4: 1$ will lead to dissolution of some contaminants in the solvent phase especially the ash forming material, which was considered to be undesirable.

As a result of the above mentioned facts, the solvent to oil ratio of $4: 1$ proved to be the better solvent to oil ratio used for treatment of used lubricating oil

Finally, it should be pointed out that these results can be very useful for the design of the extraction process to recycle waste oil at industrial scale.

\section{References}

* E-mail address: asterpu@ univ-ovidius.ro

[1]. J. Rincon, P. Canizares and M.T. Garcia, Journal of Supercritical Fluids 39, 315-322, (2007).

[2]. G. Majano, S. Mintova, Chemosphere, 78, 591598, (2010).

[3]. V.V. Ostrikov, V.D. Prokhorenkov and S.A. Nagornov, Chemical and Petroleum Engineering, 39, 5-6, (2003).

[4]. M.L. Whisman, J.W. Reynolds, J.E. Goetzinger and F.O. Cotton, Hydrocarbon Processing, 57, 141-145, (1978). 
[5]. V.V. Ostrikov and V.D Prokhorenkov., Chemical and Petroleum Engineering, 39, 5-6, (2003).

[6]. T. Bhaskar, M. Azhar Uddin., A. Muto, Y. Sakata, Y. Omura, K. Kimura and Y. Kawakami, Fuel, 83, 9-15, (2004).
[7]. R.J. Snow and S.F. Delaney, Chemeca, 77, 1416, (1977)

[8]. F. Awaja and D. Pavel, Design Aspects Of Used Lubricating Oil Re-Refining, Elsevier Science Publisher B.V., Amsterdam, 2006.

Submitted: October $5^{\text {th }} 2012$ Accepted in revised form: October $30^{\text {th }} 2012$ 